\title{
Subretinal neovascularization following ruptured retinal arterial macroaneurysm: case report
}

\author{
Neovascularização sub-retiniana secundá ria ao macroaneurisma arterial da \\ retina rôto: relato decaso
}

\author{
Raul N. G. Vianna ${ }^{1}$ \\ Aug'usto Kassuga' ${ }^{2}$ \\ Gabriela Onofre ${ }^{3}$ \\ Virginia Ecard ${ }^{4}$ \\ Mig'uel N. Burnier Jr. 5
}

\begin{tabular}{l} 
ABSTRACT \\
\hline A 51-year-oldblack woman was referred to our Retina Clinic for evaluation \\
of loss of vision in her left eye. She was previously diagnosed with a \\
ruptured retinal arterial macroaneurism (RAM) in the same eye. The \\
ophthalmoscopic examination of the affected eye disclosed a subretinal \\
lesion with some hemorrhage and exudation in the same area previously \\
diagnosed with ruptured RAM. Fluorescein angiography revealed a \\
gradually hyperfluorescent net of vessels located in the subfoveal region, \\
consistent with the diagnosis of subretinal neovascular membrane. In this \\
paper we stress the possibility of subretinal neovascularization following \\
a ruptured RAM, even as a rare event.
\end{tabular}

Keywords: Retinal neovascularization; Retinal artery/pathology; Aneurysm, ruptured/ complications; Aneurysm, ruptured/diagnosis; Fluorescein angiography

\section{INTRODUCTION}

Retinal arterial macroaneurysm (RAM) is a localized dilatation of a retinal arteriole, which usually occurs in the first three orders of the arterial tree $^{(1)}$. Overall, the main complication in patients with RAM is the rupture of the aneurysm, which results in hemorrhage and/or macular exudation ${ }^{(1-2)}$. In very few cases, rhegmatogenous retinal detachment and macular hole formation (associated or not with subretinal neovascularization) have been reported as complications following a ruptured $\mathrm{RAM}^{(3-5)}$.

This report describes the occurrence of subretinal neovascularization as a complication of a ruptured RAM.

\section{CASE REPORT}

A 51-year-old black woman was referred to our Retina Clinic for evaluation of loss of vision in her left eye (LE) of two months' duration. Medical history revealed that the patient had high blood pressure controlled with medications. Her corrected visual acuity (VA) was 20/20 in the right eye (RE) and 20/400 in the LE. Slit-lamp examination of the anterior segments was unremarkable. Intraocular tension was within normal limits in both eyes. Ophthalmoscopy of the LE revealed a deep yellow-white subretinal material of two disc diameters superiorly located in the macular region. The optic disk was normal. The fundus of the RE showed mild arterial hypertensive changes. Fluorescein angiography (FA) of the LE (Figure 1) revealed that the yellow-white subretinal material blocked fluorescence during all phases of the angiogram. Moreover, a localized arterial dilatation, 
located over the subretinal material, showed progressive fluorescence over time of examination. FA of the RE showed some microaneurysms in the retinal midperiphery.

The yellow-white subretinal material seen in the fundus of the LE was interpreted was being incompletely absorbed blood. Thus, based on ophthalmoscopic and fluorescein angiographic findings the diagnosis of ruptured RAM was made, but no treatment was indicated at that time. Control of high blood pressure was the only recommendation.

Within one year, the patient returned to be evaluated in our clinic complaining of worsening of the VA in the LE. At this time she presented with hand movements in the LE and 20/20 in the RE. Anterior segment examination of both eyes was normal, but the ophthalmoscopic examination of the LE disclosed a subretinal lesion with some hemorrhage and exudation in the same area previously diagnosed with ruptured RAM. The new lesion was strongly suggestive of subretinal neovascularization. Actually, the early transit phases of the fluorescein angiogram showed a net of vessels, which demonstrated an increase in the degree and size of fluorescence at the late phases (Figure 2). The diagnosis of subretinal neovascular membrane was then confirmed.

\section{DISCUSSION}

A structural change in the RPE with subsequent lesion at the level of Bruch's membrane most probably was the physio-

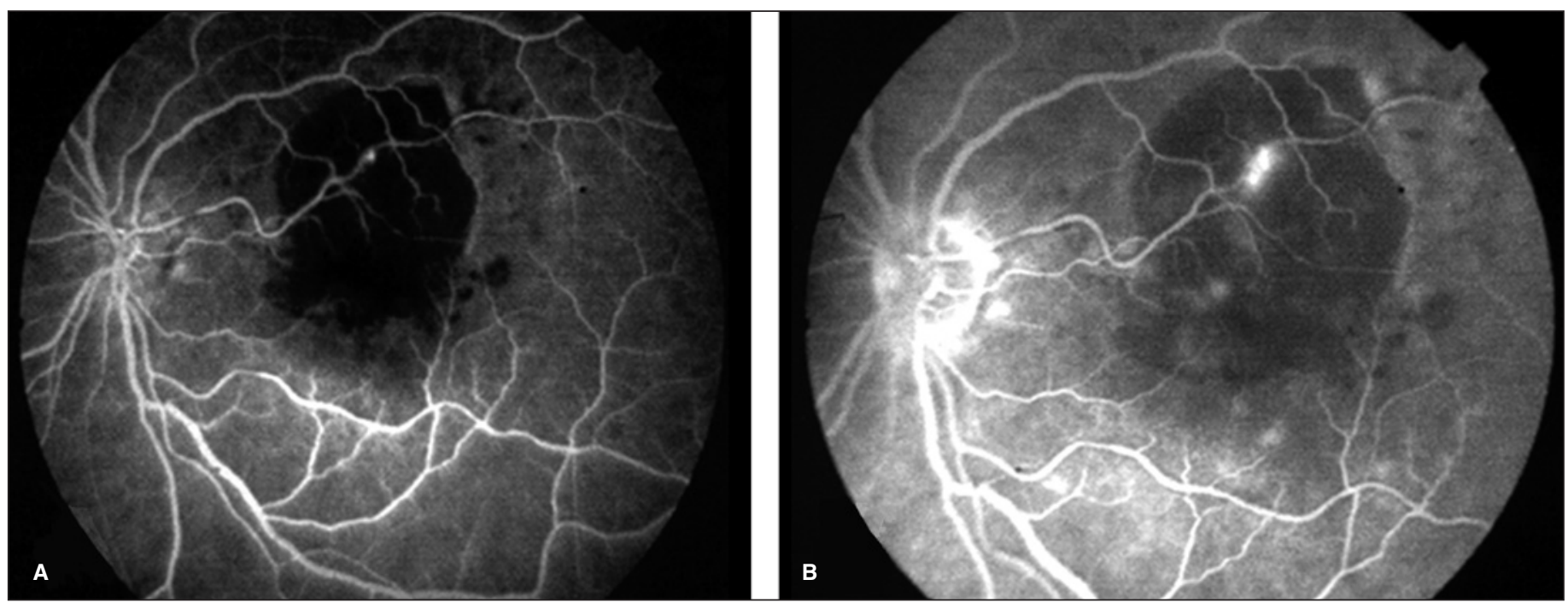

Figure 1A and B - Fluorescein angiography of the affected eye. Observe the increased fluorescence of the retinal arterial macroaneurysm. The subretinal blood masks fluorescence.

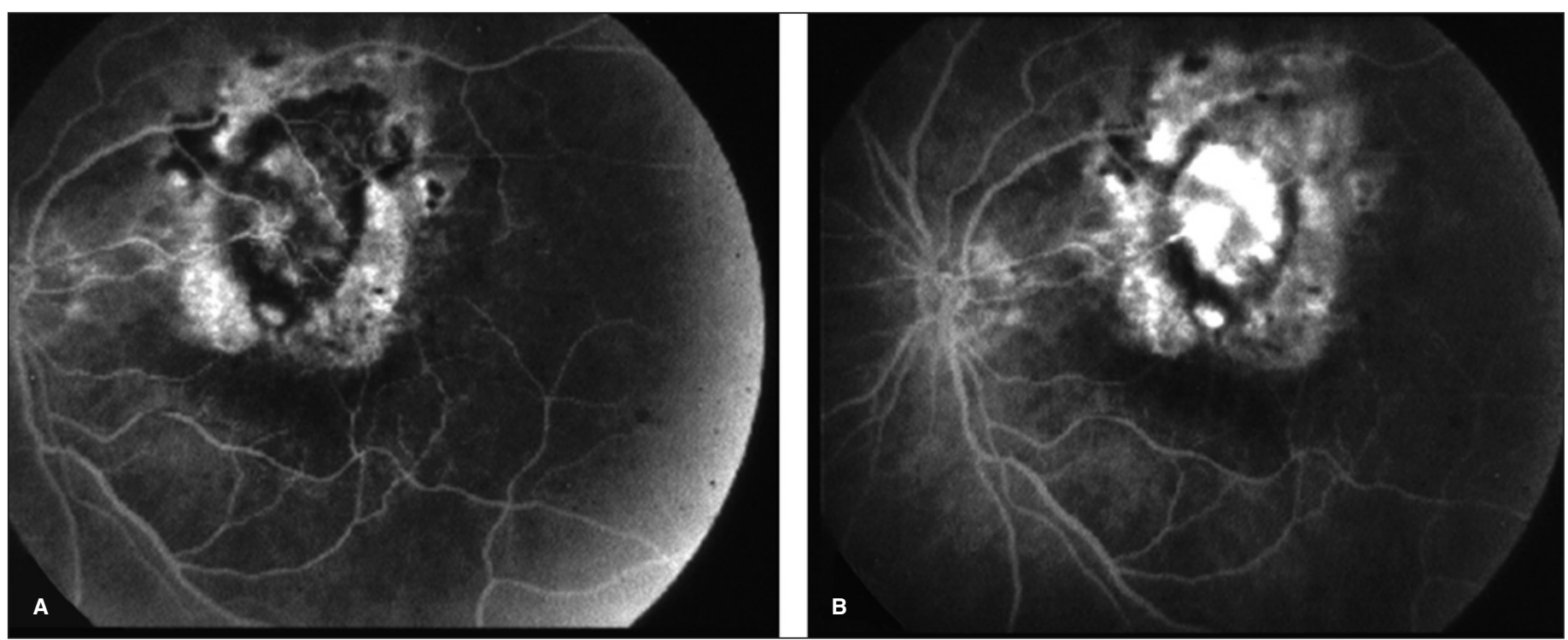

Figure $2 A$ and B - Early (A) and late (B) transit phases of fluorescein angiography demonstrating a subretinal membrane in the same area previously diagnosed with ruptured retinal arterial macroaneurysm 
pathogenic explanation for the choroidal neovascularization $(\mathrm{CNV})$ in the present case. Indeed, it has been postulated that an enzymatic or mechanical destruction of Bruch's membrane is critical for $\mathrm{CNV}$ formation ${ }^{(6)}$.

It has been known that bleeding from RAM can occur in the subretinal space, into the retina, beneath the internal limiting membrane, or into the vitreous ${ }^{(1)}$. In our case, clinical and fluorescein angiographic evidences demonstrated that the blood was located in the subretinal space, in close contact with the RPE. Histopathologic studies of RAM have shown that apart from the distention of the involved arteriole, there were fibroglial proliferation, dilated capillaries, extravasated blood, lipoidal exudates, and hemosiderin deposits surrounding the macroaneurysm $^{(7)}$. In an analogous fashion, it is possible that these abnormalities have caused structural changes in the RPE of the affected eye of our patient, with subsequent destruction of Bruch's membrane, and CNV formation.

In fact, although the physiopathogenic mechanism of CNV formation can only be hypothetical in our case, we stress on the possibility of this serious complication following a ruptured RAM, even as a rare event.

\section{RESUMO}

Paciente de 51 anos foi encaminhada ao Setor de Retina para avaliação de perda visual no olho esquerdo. A paciente apresentava o diagnóstico prévio de macroaneurisma arterial retiniano (MAR) rôto no referido olho. O exame oftalmológico revelou lesão sub-retiniana hemorrágica associada à exsudação na área previamente diagnosticada com MAR. A angiofluoresceinografia revelou hiperfluorescência gradual localizada na região subfoveal, consistente com o diagnóstico de membrana neovascular sub-retiniana (MNSR). Nosso artigo aponta para a possibilidade, embora rara, da formação de uma MNSR após MAR rôto.

Descritores: Neovascularização retiniana; Artéria retiniana/ patologia; Aneurisma rôto; Complicações; Aneurisma roto/ diagnóstico; Angiofluoresceinografia

\section{REFERENCES}

1. Levin MR, Gragoudas ES. Retinal arterial macroaneurysm. In: Albert DM, Jakobiec FA, editors. Principles and practice of ophthalmology: clinical practice. Philadelphia: WB Saunders; 1994. p.795-801.

2. Lobo RAB, Hagemann LF, Magalhães Júnior O, Moraes NSB, Bonomo PP. Tratamento do macroaneurisma arterial retiniano com edema macular crônico - acompanhamento com tomografia de coerência óptica [abstract]. Arq Bras Oftalmol. 2003;66(4 Supl): p.293.

3. Tashimo A, Mitamura Y, Sekine N, Takeda M, Ohtsuka K. Rhegmatogenous retinal detachment after rupture of retinal arterial macroaneurysm. Am J Ophthalmol. 2003;136(3):549-51.

4. Mitamura Y, Terashima H, Takeuchi S. Macular hole formation following rupture of retinal arterial macroaneurysm. Retina. 2002;22(1):113-5.

5. Murhty K, Puri P, Talbot JF. Retinal macroaneurysm with macular hole and subretinal neovascular membrane. Eye. 2005;19(4):488-9.

6. Ryan SJ, Hinton DR, Murata T. Choroidal neovascularization. In: Ryan SJ, editor. Retina. $3^{\text {rd }}$ ed. St. Louis: Mosby; 2001. p.1003-23.

7. Fichte C, Streeten BW, Friedman AH. A histopathologic study of retinal arterial aneurysms. Am J Ophthalmol. 1978;85(4):509-18. 